\title{
“UM SONHO PARA AS CIÊNCIAS SOCIAIS"
}

\section{“A DREAM FOR THE SOCIAL SCIENCES"}

\author{
Giovanni Boaes* \\ Maylle Alves Benício
}

\section{LAHIRE, Bernard. L'interprétation Sociologique des rêves. Paris: La Découvert, 2018.}

"O que podem dizer os sonhos sobre a vida dos indivíduo e das sociedades em que vivem?" “Como as experiências sociais dos 'sonhadores' contribuem para tramar seu imaginário, mesmo nos momentos quando a consciência intencional não governa o fluxo das imagens?" Essas são questões que norteiam a aventura sociológica de Lahire em "terra incógnita" da expressão onírica, cujo produto é o livro que ora resenhamos. Nesta aventura, o autor pretende estender o alcance da sociologia disposicionalista e contextualista da ação, voltando-se para o mais recôndito do psiquismo humano, a fim de demonstrar que o "inconsciente" é "social", e que não pode ser resumido a um "id", deve ser tratado como uma "consciência involuntária", representada pelo passado incorporado na forma de esquemas de disposições. "L'interprétation sociologique des rêves", como diz Lahire, é o bilhete de entrada para o sonho nas ciências sociais, ${ }^{1}$ a partir de uma perspectiva disposicionalista e contextualista ao mesmo tempo.

A obra foi lançada em 2018 pela editora La Découverte, sem tradução ainda para o português, e é a mais recente da vasta produção do sociólogo francês. Com 487 páginas, está estruturada em 13 capítulos - precedidos por uma introdução geral -, duas conclusões e uma coda. Deverá ser sucedida por outro volume. O primeiro livro dedica-se à construção de uma teoria integradora (e empiricamente pertinente), a partir dos conhecimentos teórico-empíricos já produzidos sobre o sonho, cujo produto se condensa na fórmula geral de interpretação dos

\footnotetext{
${ }^{*}$ Professor do Departamento de Ciências Sociais da Universidade Federal da Paraíba (UFPB)/Brasil. Doutor em Sociologia pela Universidade Estadual Paulista (UNESP)/Brasil. E-mail: giboaeas@gmail.com

${ }^{* *}$ Doutoranda do PPGS (Programa de Pós-graduação em Sociologia da Universidade Federal da Paraíba (UFPB)/ Brasil. E-mail: maylle.benicio@gmail.com

1 É válido mencionar que autores, a exemplo do francês Roger Bastide ou do brasileiro José de Souza Martins, e de outros que serão citados pelo próprio Lahire, anteviram a necessidade de se trabalhar o sonho sob uma perspectiva sociológica e implementaram projetos de pesquisa a respeito do tema. Na verdade, o sonho já fez sua entrada como objeto das ciências sociais, antes desta obra de Lahire, embora para ele, os livros que o antecedem, não se dedicaram ao processo de produção do sonho em si, preocuparam-se em investigar as atividades humanas que ocorrem em torno do relato do sonho, de como este é utilizado, como é apropriado e que práticas e discursos pode suscitar nas diferentes épocas e culturas. Por outro lado, a sua sociologia do sonho, engloba essa contribuição, mas dedica-se com prioridade a perceber como a atividade humana engendra o sonho, em outras palavras, ocupa-se do processo em si de fabricação das imagens do sonho e de seu relato.
} 
sonhos. É pertinente observar o engajamento de Lahire com a asserção da sociologia como uma ciência empírica. Conforme ponderam Véran e Vandenberghe (2016), o trabalho de campo é para o autor imprescindível ao ofício do sociólogo, pois é o espaço da descoberta empírica que proporcionará a exploração teórica e a reformulação de conceitos. Todavia, neste livro, Lahire dedica-se à discussão teórica do tema, introduzindo, sob sua ótica, o sonho no campo das ciências sociais.

O segundo livro se dedicará à interpretação de corpora específicos de sonhos, aplicandolhes a fórmula geral e seus instrumentos metodológicos, ou seja, serão apresentadas as biografias sociológicas dos sonhadores e sonhadoras que têm sido entrevistados ao longo da pesquisa, analisadas à luz da teoria integradora construída anteriormente. É com muita expectativa que aguardamos a publicação do segundo volume.

No geral, a sua proposta procura demonstrar que o comportamento dos indivíduos adormecidos se expressa nos sonhos e, como todo comportamento humano, esse pode ser compreendido a partir da teoria sociológica geral da prática, em escala individual. O sonho é mais uma expressão humana que se distribui no continuum de todas as formas de expressão humana, nada havendo nele de misterioso, sobrenatural ou insondável. A preocupação em tornar os sonhos objeto da sociologia, acompanha o autor desde o início de sua produção. Em "O homem plural" (2002), por exemplo, diz haver uma proximidade entre a sociologia dos sonhos e uma sociologia da ação (p.129)2. Contudo, foram necessários mais de vinte anos de dedicada pesquisa para que "A interpretação sociológica dos sonhos" pudesse tomar forma e vir à tona.

O grande desafio que Lahire se propôs a encarar, ao gestar essa obra, foi o de estudar o sonho com o devido rigor científico e acadêmico, abrindo o caminho para uma sociologia do sonho que não se confundisse com a psicanálise. Esse objeto que se coloca como inquietantemente sedutor e, à primeira vista, "espontaneamente indecifrável" é comparado a um castelo de contos de fadas, cercado por fossos e protegido por um dragão. Os fossos e o dragão referem-se, em parte, às marcas profundas deixadas pelas tentativas passadas de interpretação dos sonhos, particularmente às ideias de Freud e dos seus seguidores que, segundo Lahire, criaram vícios interpretativos difíceis de serem desmanchados.

Contudo, Lahire de forma alguma coloca-se em profunda oposição ao modelo de interpretação dos sonhos proposto por Freud. Pelo contrário, é com base nas conquistas desse modelo que o sociólogo se esforça para corrigir o que considera como fraquezas, erros e falhas contidos nele, aproveitando os vários avanços científicos que ocorreram desde a publicação do Traumdeutung. Lahire reconhece os méritos de Freud e enfatiza o papel crucial que desempenhou: foi pioneiro em reconhecer que os sonhos não são uma produção desordenada e randômica de

2 Nas suas obras mais recentes, com ênfase para "Kafka, Franz. Élements pour une théorie de la création littéraire" (2010), é possível perceber o avanço de Lahire em direção à compreensão do terreno onírico. Nessa referida obra, por exemplo, o autor descortina a questão da "problemática existencial", que será elemento fundamental na sua posterior elaboração da interpretação sociológica dos sonhos. 
imagens, mas que possuem lógicas razoáveis e, assim, passíveis de interpretação.

O sonho, que Bernard Lahire define como sendo o mais íntimo dos diários, é um dos espaços vazios que ainda não havia sido colorido de forma satisfatória pelas ciências sociais, um lugar por onde poucos sociólogos só muito timidamente se arriscaram a caminhar; ao contrário de psicólogos, psicanalistas e neurocientistas.

De partida, Lahire previne o leitor quanto ao seu estilo de escrita e produção intelectual: uma linguagem que não se prende ao obscurantismo das recorrentes produções francesas que se preocupam mais em seduzir do que em demonstrar e explicar. Alerta, também, que o avanço do conhecimento não pode acontecer sem a recorrência ao passado e enfatiza a necessidade de ultrapassar as barreiras disciplinares. Nesse sentido, agrega conhecimentos de diversas áreas e de temporalidades distintas, propondo uma teoria integradora dos determinismos sociais dos sonhos. Sua aventura sociológica por essas terras incógnitas é justamente uma forma de transpassar as fronteiras impostas pela especialização disciplinar, tema importante para o autor e já significativamente discutido em outros livros seus, com destaque para Monde pluriel (LAHIRE, 2012).

O ponto de partida é uma revisão crítica acerca do progresso da ciência dos sonhos, tomando a Interpretação dos sonhos, de Freud como um marco. Descreve sobre dois momentos importantes no cenário da interpretação dos sonhos: um divinizado, supersticioso, divinatório e elitizado, seguido de um segundo momento que começa a estabelecer-se a partir do século XI, no qual é possível perceber uma dessacralização e uma democratização dos sonhos. Os sonhos das pessoas comuns passam a ter importância, da mesma forma que os sonhos dos reis, santos e pessoas ilustres. Os sonhos deixam de ser vistos como obra de anjos e demônios e tornam-se fenômenos psicológicos e autobiográficos. No século XVII, por seu turno, será formado com Descartes, o paradigma fisiológico e individualista que dará o rumo, doravante, aos estudos sobre o sonho. A forte influência desse paradigma irá limitar a pertinência dos fenômenos sociais na lógica de formação dos sonhos.

De Descartes a Jérôme Richard, as interpretações do sonho vão se aproximando da forma desenvolvida por Freud. Apoiado no pensamento de muitos autores que o antecederam, Freud desenvolverá sua interpretação dos sonhos, e diz, Lahire (2018, p. 21): "alguns dos pontos de sua reflexão não são verdadeiramente inéditos... Freud, como todo cientista original, não inventou grande coisa". Porém, seu papel foi muito significativo na montagem do quebra-cabeça. Aqui Lahire entra em desacordo com Michel Foucault quando este declara que o sonho entra em cena com o livro A interpretação dos sonhos. Lahire afirma que a entrada do sonho no campo da significação humana simplesmente precedeu Freud em alguns milhares de anos, e no campo das ciências humanas, há mais de um século. Depois de Freud, muitos irão fazer críticas à sua interpretação dos sonhos, dentro da psicanálise ou fora dela. Então, "nada começa e nem termina com Freud" (LAHIRE, 2018, p. 23). Mas, o autor é levado a reconhecer que Freud foi o primeiro a aventar "um grande modelo teórico sintético e integrador para o estudo dos sonhos" (p. 25). 
Quanto ao progresso da ciência dos sonhos, diante da panóplia de explicações, Lahire afirma que esse tem acontecido paulatinamente. Todavia, encontra-se no fogo cerrado entre um relativismo radical e um dogmatismo cientificista, ao passo que seria necessário encontrar um meio-termo entre essas duas posturas para obter o real progresso, o que, obviamente, pretende fazer. Depois de avaliar a contribuição de Freud e de outros pensadores, Lahire chega à conclusão de que seria imperativo o desenvolvimento de uma teoria do sonho mais justa, mais rigorosa e mais coerente do que a de Freud.

A teoria que ele submete ao exame, nesta obra, é uma teoria do tipo disposicionalistacontextualista que permitirá pensar o sonho como uma forma particular de expressão, ou produção simbólica, dentro do conjunto das formas de expressão humana. Apoia-se, para isso, sobre as aquisições da sua sociologia em escala individual que envolve o cruzamento entre disposições incorporadas e contextos de ação (e de expressão).

A possibilidade de estudar sociologicamente o sonho pressupõe, para o autor, uma transformação nas ciências sociais, que terá que rever seus instrumentos teóricos e metodológicos de modo que permitam conhecer o sonho sem desvirtuá-lo. Isso é vantajoso para a sociologia, porque mexe com sua própria estrutura. É um desafio estimulante que impulsiona a sociologia a refletir sobre si mesma, suas teorias e seus métodos, bem como sobre o exato significado da palavra "social". Somado a isso, a temática obriga os sociólogos a reverem as relações entre o cerebral e o social ${ }^{3}$, algo que tem sido esquecido nas formulações sociológicas ordinárias que se dedicam apenas à vida acordada.

O sonho é uma realidade individual intrinsicamente social. Portanto, não pode ser visto como algo isolado no indivíduo, insular, nos limites da caixa craniana. Ele se insere na história do "sonhador" e na rede de obrigações colocadas pela sociedade, pelo grupo.

Ao analisar a obra de autores que se arriscaram a dizer algo sobre os sonhos na perspectiva das ciências sociais - entre eles, Durkheim, Halbwachs, Roger Bastide e Jean Duvingnaud -, enfatiza que esses cientistas sociais, com destaque para os antropólogos, têm feito uma ciência dos usos dos sonhos, que também pode ser lida como uma "ecologia social do sonho". Embora seja uma abordagem legítima, não constitui uma forma decisiva para se compreender o sonho como objeto plenamente social. O sonho é social não só porque é compartilhado, comentado, interpretado segundo os quadros sociais de crença e expectativas culturais coletivas. Ele é social de cabo a rabo, tanto nos seus móveis, e nas modalidades de sua fabricação, como nas regularidades objetiváveis de seu conteúdo.

Lahire também revisita as abordagens literárias que se utilizam da análise de conteúdo para interpretar os sonhos. Ele assinala que, apesar de acertarem ao admitirem a chamada hipótese da continuidade, limitam-se a decompor o sonho em séries de elementos que são classificados em categorias (objetos, lugares, animais, situações, palavras etc.) para daí extrair as frequências de ocorrência de cada categoria. O erro principal desse tipo de análise, a seu 
ver, é deterem-se ao conteúdo manifesto do sonho, desprezando os mecanismos específicos que operam na passagem da vida acordada para o sonho. Desprezam, por exemplo, o passado incorporado daquele que sonha e que não se manifesta no conteúdo do sonho, assim como as transformações metafóricas e simbólicas, os efeitos de condensação, de substituição etc. que atuam na produção imagética dos sonhos.

Sobre o assunto, o sociólogo alerta: "uma teoria dos sonhos não será completa se se contentar em fazer análises quantitativas de conteúdo sem buscar saber o que há por trás das imagens, das sensações e das palavras, o que constitui o pano de fundo estruturante que permite a sua fabricação" (LAHIRE, 2018, p. 81). Desse modo, um relato de sonho não pode ser simplesmente tomado como um texto literário. Há bastante diferença quanto ao gênero e às condições sociais e simbólicas de produção de cada um. Sem falar que a decomposição dos sonhos leva o analista a perder a visão global do sonho. Mas, de qualquer forma, reitera que esses estudos são importantes para avançar para uma ciência da produção dos sonhos e com ela mergulhar no significado social da vida onírica.

"O que faz do sonho um fato profundamente social?" Para responder a essa questão, Lahire vai relembrar do que já abordou em livros anteriores: a problemática acerca do que se pode entender pela palavra social. Vai, então, diferenciar a identificação clássica entre coletivo e social que acabou relegando os fatos individuais para o campo da psicologia. Como já fora visto em "Homem plural” (2002), "Retratos sociológicos" (2004), "A cultura dos indivíduos" (2006), entre outros, o indivíduo é plenamente social, pois é produto do processo de socialização vivido em grupos ou instituições que frequentou ao longo de sua vida. O selo "social", nesses moldes, estará impresso no passado incorporado na forma de esquemas de disposições ou resumo de experiências. Contudo, apelar para o passado incorporado é apenas um aspecto da análise, pois o outro lado se refere aos diversos contextos ou quadros de interação que atuarão na ativação ou inibição das disposições. Porém, é preciso ter em conta que o social não se remete apenas à copresença interindividual, ao passo que aquele que age na ausência de outros ainda assim merece a designação de social, como é o caso do sonhador.

O sonho pode ser interpretado a partir da relação estabelecida com a vida daquele que sonha, suas preocupações, tensões, conflitos, desejos e medos, ou seja, a chamada hipótese da continuidade. "Verdade que foi percebida desde os primeiros séculos da era cristã por gregos e romanos" (LAHIRE, 2018, p. 93). A questão que se interpõe se refere a saber o que é a vida ou o vivido da pessoa que sonha, e, principalmente, qual tipo de metodologia é necessária para se reconstruir o "vivido" do sujeito e como relacioná-lo com os seus sonhos. Essa metodologia será discutida minuciosamente no décimo terceiro capítulo do livro, sintetizada em sete passos principais (p. 415).

Do ponto de vista da sua sociologia disposicionalista e contextualista, a questão se resolve cruzando-se os esquemas de experiências incorporadas ou o estoque de disposições e os enredos oníricos; as problemáticas existenciais e as problemáticas oníricas; elementos da biografia 
sociológica do ator e a encenação onírica. Trata-se de analisar os elementos estruturantes da vida dos atores para se compreender a natureza das intrigas (enredos) elaborados em seus sonhos. Mas, isso não significa que o sonho seja a simples transcrição, sob a forma de um relato onírico, da vida do sujeito. Apoiando-se em definições já apresentadas por outros autores, Lahire reforça as caraterísticas do sonho, certamente para respaldar sua fórmula geral de interpretação dos sonhos:

[...] as propriedades psicológicas e formais da atividade onírica já foram bastante descritas, analisadas e validadas por vários autores, bastante diversificados. Entre elas, encontramos a ausência de planificação, de reflexividade e de controle da narração presentes no sonho, o que contribui para criar a impressão de incoerência; o caráter implícito de uma linguagem privada; a importância das imagens, da simbolização e de um uso visual da metáfora; a presença do que Freud chamou "condensação", pela qual podem ser combinadas imagens provindas de várias fontes representando situações, lugares, objetos ou pessoas diferentes que possuem alguma analogia em relação ou sobre um outro; ou ainda a tendência ao exagero emocional ou à dramatização de situações (quando, por exemplo, o sonhador vê morrer a sua frente pessoas com as quais mantém um simples ressentimento) (LAHIRE, 2018, p. 95).

Essas características serão analisadas detalhadamente pelo autor ao longo da obra. Cada uma delas merecerá um capítulo correspondente. Para exercitar uma sociologia disposicionalistacontextualista em escala individual sobre os sonhos, esses deverão ser compreendidos a partir de três grandes elementos, articulados em uma fórmula geral de interpretação dos sonhos e detalhados no decorrer do livro:

1. Os elementos recorrentes do estoque de disposições do sujeito e o estado de sua problemática social. Isto será alcançado com a elaboração da biografia sociológica do sonhador;

2. As circunstâncias imediatas da vida diurna, especialmente, a véspera do sonho, pois elas serão importantes para suscitar o enredo onírico a partir da ativação de certos esquemas incorporados. Estas serão obtidas por meio de entrevistas com o sujeito;

3. O quadro específico da expressão onírica que se caracteriza pelo isolamento do sujeito, durante o sono, das interações sociais ordinárias e pela ausência de demanda do entorno, afrouxamento da capacidade de controle narrativo, escuridão, silêncio, a necessidade de se exprimir essencialmente em imagens, e a predominância de uma linguagem interior ou privada cuja característica é a elipse, pois pressupõe uma comunicação de si para si. O quadro do sono, portanto, apresenta uma série de "exigências" ou lógicas no processo de produção onírica.

A fórmula geral de interpretação dos sonhos a que Lahire chega envolve, portanto, elementos: circunstanciais, conjunturais e estruturais. Funciona como uma derivação da sua fórmula geral do estudo das práticas (disposições + contexto $=$ prática), que precisará ser 
complexificada para se adaptar ao sonho. No processo de adaptação, faz-se necessário acrescentar elementos suplementares. Assim, o processo da interpretação dos sonhos será divido em três etapas: a primeira é a que antecede o sono (éveil ante-rêve), nela a pessoa encontra-se acordada. É quando se formam os estímulos internos que desempenharão papel importante na segunda fase. A primeira etapa corresponde, geralmente, à véspera da ocorrência do sonho, mas, conforme alguns estudos de neurocientistas, pode se estender a até catorze dias da ocorrência do sonho. A segunda etapa se refere ao sono propriamente dito (temps de sommeil), ou quadro do sono, quando se desenrolam os enredos oníricos com suas imagens e sensações. A terceira diz respeito ao momento de despertar e relembrar dos sonhos, é o tempo de relatá-lo (éveil post-rêve).

A dinâmica interpretativa se processa nos moldes da sociologia em escala individual, relacionando disposições e contextos: durante o dia, forma-se um contexto particular (eventos, interação vista ou vivida, algo que se leu ou assistiu etc.) que irá desencadear elementos do passado incorporado do sujeito (estado de sua problemática existencial e suas disposições ou esquemas incorporados). Estes funcionarão como estímulos internos que serão somados aos outros estímulos advindos do quadro do sono.

$\mathrm{Na}$ situação acordada que antecede o sonho, acontecimentos, gestos e palavras que apresentam analogias com experiências passadas irão ativar partes do esquema de disposições incorporadas. Isto pode, então, mobilizar imagens ligadas a momentos diferentes do passado dos "sonhadores" que se expressarão por analogias (semelhança e contiguidade).

No quadro do sono, onde o sonho se desenrolará, a ênfase será dada às condições cerebrais, psíquicas, semióticas e sociais do sonho. O indivíduo se afasta das interações, tornando-se ausentes as demandas e pressões de outros. As percepções noturnas são integradas e traduzidas pela lógica do sonho. Há uma perda do controle reflexivo e diminuição da vigilância planificadora e da narração. Prevalece a modalidade de comunicação de si para si, ou seja, uma linguagem interna implícita comandará o processo de fabricação dos sonhos. A isso se soma um relaxamento das censuras formais e morais - esse duplo afrouxamento é o tema do capítulo seis. Com esses elementos reunidos, processa-se a transformação ou tradução dos esquemas de experiências em esquemas oníricos, caracterizados pela visualização (predomínio das imagens), exagero/dramatização, simbolização, metaforização, condensação.

Quando o indivíduo desperta, inicia-se a terceira fase, na qual ele se lembrará do sonho e fará o relato (oral ou escrito). Daí, então, tem-se a chamada elaboração secundária, ou seja, um relato que irá traduzir a linguagem onírica para a comunicação com outros, o que reativará as exigências da linguagem formal e usual. Isso implica que a narrativa pode ser modificada conscientemente ou não, tanto pelas exigências exteriores da língua quanto pelo repertório e competências gramaticais do narrador.

Enfim, é possível dizer que a fórmula geral de interpretação do sonho permite compreender por que o "sonhador" não pode entender imediatamente, ao despertar, as imagens oníricas por ele mesmo produzidas. Essa situação se explica, em grande parte, pelo fato de que os seres humanos 
têm uma história e que o passado vivido não desaparece, ele continua a existir sob a forma de experiências incorporadas "prontas para entrarem em ressonância com as situações presentes, a reaparecer na superfície a todo momento, no estado acordado e durante a noite" (p.111).

É fundamental perceber que a fórmula de Lahire assemelha-se em diversos aspectos à proposta por Freud. Foi o psicanalista quem articulou de forma mais direta e consistente, pela primeira vez, a relação entre um passado incorporado (sob a forma de inconsciente), e os acontecimentos presentes (restos diurnos) na explicação do sonho. Entretanto, o que Lahire coloca em xeque, a todo momento, são algumas generalizações teóricas abusivas e estereotipadas, presentes no legado de Freud e de seus seguidores. Por exemplo: a) o peso demasiado conferido ao papel das experiências socializadoras familiares; b) a universalização e a naturalização de esquemas que são social e temporalmente localizados, como o complexo de Édipo; c) o privilégio da explicação sexual que afirma ser todo sonho a realização de desejo sexual infantil; d) o privilégio do conteúdo latente em prejuízo do conteúdo manifesto do sonho; e) a não apreensão do poder e da dominação em suas várias formas, limitando-a às relações parentais estreitas, sempre marcadas pelo conteúdo sexual etc.

Em suma, ir além da observação da vida humana em estado de vigília, mergulhar no mundo da fabricação dos sonhos e não apenas sonhar que essa é uma abordagem possível para a sociologia, mas demonstrá-la efetivamente em uma densa, coerente e bem argumentada obra, é indubitavelmente o grande mérito alcançado por Bernard Lahire em "A interpretação sociológica dos sonhos". Cremos que o livro, em seu conjunto, é uma espécie de "curso avançado" sobre a ciência dos sonhos, e que deve ser lido não só por sociólogos, mas por todos aqueles que possuem algum tipo de interesse sobre o assunto, desde os apenas curiosos até os psicoterapeutas, passando por cientistas sociais (antropólogos, historiadores, cientistas políticos etc.) neurocientistas e psicólogos.

É fato que os princípios que engendram a interpretação já haviam sido estabelecidos por outros autores, como reconhece o próprio Lahire, ao dizer que sua fórmula de interpretação dos sonhos é prima da fórmula proposta por Freud em 1900. O prolongamento reside na correção dos sentidos dos elementos da fórmula. Nesse aspecto, Lahire abre a perspectiva freudiana, ampliando a sua concepção de social, rejeitando o conceito de inconsciente, descartando os reducionismos por trás da afirmação de que os sonhos são realizações de desejos, sempre infantis e sexuais. Ademais, abrange o significado do elemento desencadeador do sonho, que deixa de ser um acontecimento único (trauma e recalque) e se volta para diversos contextos, ou série de elementos.

Esta obra também representa um marco em suas produções e traz pistas sobre possíveis aberturas e reformulações acerca de sua fórmula geral das práticas, desenvolvida ao longo de sua trajetória. O fato de ele agregar um elemento chamado "problemática existencial" à fórmula de interpretação dos sonhos ${ }^{4}$ leva-nos a pensar que, apesar de sua definição sobre o que entende

4 Elemento que se sedimenta na elaboração da biografia sociológica de Kafka (LAHIRE, 2010), e que se encontra ausente nas primeiras obras de Lahire. 
por "existencial" negar qualquer filiação à filosofia existencialista ou a qualquer outra filosofia, isto pode representar uma inflexão, ainda que a contragosto, ${ }^{5}$ no seu determinismo sociológico.

É com essa impressão que neste livro vemos Lahire dar mais visibilidade às “competências", frente às disposições e contextos; vemos o autor adotar outra configuração de sinais para ligar os elementos de suas fórmulas (substitui os sinais “+” " “=" por setas curvas, simulando movimentos) com aspecto mais dialético e circular; refere-se a contextos fortes e contextos fracos, qualidades que, até produções recentes, só pertenciam às disposições. Enfim, como ele mesmo destaca, para a sociologia, estudar o sonho no que ele tem de específico, ou seja, como uma forma de expressão humana, levará necessariamente à transformação da própria sociologia, e acreditamos que a primeira a se beneficiar com esses efeitos será a sociologia em escala individual.

Quanto à apresentação do texto, é perceptível um estilo claro e fluido, recorrendo a exemplos e diagramas para facilitar o entendimento. Talvez o que menos agrade ao leitor pouco acostumado ao estilo de Lahire seja a prevalência de argumentos do tipo ad nauseam que o levam a repetir várias vezes as mesmas informações de maneira difusa ao longo da obra, o que pode tornar a leitura um pouco cansativa. Porém, no geral, a sua adesão ao princípio de "não turvar as águas para fazer parecê-las profundas", como diria Nietzsche, garante a leitura e o entendimento desta obra de fôlego - ao menos para quem já possui algum conhecimento prévio de suas principais temáticas - sem muitas dificuldades.

\section{Referências}

LAHIRE, Bernard. A cultura dos indivíduos. Porto Alegre: Artmed, 2006.

LAHIRE, Bernard. Homem plural: os determinantes da ação. Petrópolis: Vozes, 2002.

LAHIRE, Bernard. Kafka, Franz. Élements pour une théorie de la création littéraire. Paris: La Découverte - Laboratoire des Sciences Sociales, 2010.

LAHIRE, Bernard. Monde pluriel: penser l'unité des sciences sociales. Paris: Éditions du Seuil, 2012.

LAHIRE, Bernard. Retratos sociológicos: disposições e variações individuais. Porto alegre: Artmed, 2004.

LAHIRE, B; ROSENTAL, C. (org.) La cognition au prisme des sciences sociales. Paris: Éditions des archives contemporaines, 2008.

VÉRAN, J. F; VANDENBERGHE, F. Novas Sociologias: um exercício de teoria comparativa. In: VANDENBERGHE, F.; VÉRAN, J. F (org.). Além do habitus: teoria social pós-bourdieusiana. Rio de Janeiro: 7 letras, 2016. p. 9-25.

Recebido em: 1/04/2019

Aceito em: 14/04/2019

5 Acreditamos que Lahire expresse bem o seu determinismo na Conclusão 2: O sonho, a vontade e a liberdade (p. 431-439). Contudo, apesar dessa afirmação do determinismo, entendemos que A interpretação sociológica dos sonhos sinaliza para rumos mais relativistas. Sobre o determinismo de Lahire, ver a entrevista neste volume: "O indivíduo, a existência e a teoria social - uma entrevista com Frédéric Vandenberghe”, realizada do Rodrigo Vieira de Assis. 